\title{
Organization
}

\section{"You Can't Pick Up a Phone and Talk To Someone": How Algorithms Function as Biopower in the Gig Economy}

\begin{tabular}{|c|c|}
\hline Journal: & Organization \\
\hline Manuscript ID & ORG-19-0214.R3 \\
\hline Manuscript Type: & Special Issue: Dark Side of Digitalization \\
\hline Keywords: & $\begin{array}{l}\text { Algorithms, Gig economy, Platform Capitalism, Resistance, Biopower, } \\
\text { Uber }\end{array}$ \\
\hline Abstract: & $\begin{array}{l}\text { This paper asks why there is so little collective dissent and mobilised } \\
\text { resistance in the gig economy, especially when labour-based digital } \\
\text { platforms are used. We suggest part of the answer lies with } \\
\text { 'management by algorithm'. Drawing on an empirical study of Uber } \\
\text { drivers in Australia, we found that algorithms function as a form of } \\
\text { biopower, a concept introduced by Michel Foucault ( } 2008 ; 2007 ; 2003) \text {. } \\
\text { As Uber drivers 'life processes' are put to work, fragmentation, isolation } \\
\text { and resignation ensue. We explore the implications that our findings } \\
\text { have for appreciating how biopower operates within platform capitalism } \\
\text { and beyond. }\end{array}$ \\
\hline
\end{tabular}

\section{SCHOLARONE Manuscripts}




\title{
"You Can't Pick Up a Phone and Talk To Someone": How Algorithms Function as Biopower in the Gig Economy
}

\begin{abstract}
This paper asks why there is so little collective dissent and mobilised resistance in the gig economy, especially when labour-based digital platforms are used. We suggest part of the answer lies with 'management by algorithm'. Drawing on an empirical study of Uber drivers in Australia, we found that algorithms function as a form of biopower, a concept introduced by Michel Foucault (2008; 2007; 2003). As Uber drivers 'life processes' are put to work, fragmentation, isolation and resignation ensue. We explore the implications that our findings have for appreciating how biopower operates within platform capitalism and beyond.
\end{abstract}

Key words: algorithms, biopower, gig economy, platform capitalism, resistance, Uber

\section{Introduction}

The application of the 'free market' ideals associated with neoliberalism (Harvey, 2005) to the employment relationship, have significantly eroded worker protections associated with the post-war capital/labour compact (Kalleberg, 2018). Employers' power has increased also thanks to the newfound capacity to externalise costs via various forms of indirect employment systems. We focus in particular on a technologically enabled variant of this: digital platform labour (Hill, 2015; Prassl, 2018; De Stefano, 2015).

While the electronic mediation of social activity more generally may have once held potential for open collaboration (Levine and Prietula, 2014) and participatory citizenship (Stevenson, 2015; De Angelis, 2003), large swathes of the 'digital commons' is now subservient to capitalism (Ossewaarde and Reijers, 2017), including how individuals generate income. This has seen the marketization of human lives far outside the time and space where work has traditionally been undertaken (Zuboff, 2015), with platforms devising ways to extract profits from individuals' spare time, their idle motor vehicles, second-hand belongings, and unoccupied accommodation (Srnicek, 2016). According to this business model, individuals are more or less permanent/continuous carriers of corporate values and almost any aspect of human life can (and should) be monetized, with the extracted value immediately 'reinvested' in consumption, fuelling a perpetual cycle (West, 2018).

Researchers have recently become aware of the significant 'negative externalities' associated with this business model and their impact on various stakeholders in and around the 
employment relationship (Kessler, 2018; Stanford, 2017; Shell, 2018). Indeed, the reduction of all social relationships to 'spot' market transactions and use of digital interfaces in place of human interactions can have some detrimental consequences for workers (Scholz, 2016; Wood et al., 2019) - as dramatically portrayed in Ken Loach's movie, Sorry We Missed You. This presents a puzzle in relation to the gig economy: despite educational attainments and the widespread availability of communication tools that could effectively mobilize collective dissent, workers in the gig economy frequently appear powerless. Indeed, the picture we get from the extant research is of a defeated, supine and largely non-resistant workforce. Loyalty or exit (Hirschman, 1970) appear to be the predominant alternatives.

We argue that this lack of collective resistance is due to the techniques of power that are used by platform firms to regulate their de facto workforce. No doubt traditional capital/labour power relations are at play; yet the use of digital mediators and the formal classification of selfemployment clearly introduce additional dynamics into these relations. In this paper we specifically focus on the use of algorithms to reveal a novel form of power, one that encompasses the 'bios' or life processes of workers, rather than just their formal labour time. Algorithms are a set of rules modulated by computer programs, often using Artificial Intelligence (AI), to regulate supply and demand in the gig economy. We employ the notion of biopolitics or biopower to examine the way in which algorithms shape the political possibilities of participants under platform capitalism. The neologism 'biopolitics' (or biopower) was discussed by Michel Foucault in a series of lectures delivered in the 1970s to analyse the insinuation of market values into everyday life (Foucault, 2008; 2007; 2003) Biopower represents a form of regulation that utilises life itself, individuals' bodies, time, personalities and everyday decisions, much of which falls outside the typical 9-to-5 pattern of employment (Author, 2014a; Moisander et al., 2018).

We submit that platform firms epitomise this expression of power since it encourages lowwage or unemployed individuals to fill up their evenings and weekends with incomesupplementing activities. Company rhetoric celebrates this as giving workers 'flexibility' to earn income whenever they want. However, the world has not changed so much that weekends and weekdays are interchangeable (Yu and Peetz, 2019). Thus work and life, as Foucault (2008) forewarned, become impossible to disentangle in this sector. Ridesharing platforms, for example, incentivise workers to leave home to work during 'surge' periods which are usually evenings and weekends, deploying techniques derived from behavioural economics to 'nudge' drivers so that the 'choice' feels more natural. 
While there have been some cases of collective resistance to platform capitalism (for instance, the class actions against Deliveroo and Uber), we contend that resistance has been remarkably absent in this sector, an observation others have made too (Stanford, 2017; Wood et al., 2019; Scholz, 2016). This is surprising given the exploitation and hostile management practices that frequently accompany labour-based digital platforms. In this paper, based upon an empirical study of Uber, we argue that the use of algorithms is one reason why platform capitalism has so successfully displaced resistance. While this mode of biopower harvests value from the full 'life' of workers, it paradoxically dehumanises management, replacing supervisors with a set of highly depersonalised and disembodied commands. Being faceless, algorithmic constraints are not construed as decisions by antagonists, but 'naturalised' and treated as inevitable hurdles that can only be navigated or 'gamed'. Moreover, with the help of AI, any resistance that does occur is deflected onto co-workers or other stakeholders instead of employers. In this context, paradoxically, individual acts of defiance end up functioning to the platform's advantage, sustaining the power asymmetry between employers and workers.

In making this argument, the paper is structured as follows. First, we give an overview of digital on-demand employment, focusing on the use of algorithms as a significant regulation mechanism. Second, we introduce the concept of biopower, explaining its utility for describing the power dynamics that characterize the relations between employers and employees in the gig economy, highlighting the intermediary role played by algorithms and AI. Third, in order to understand how resistance is both thwarted and deflected, we draw on a case study of Uber drivers in Australia. And fourth, the implications for studying the gig economy and the emergent patterns of employment it signals are discussed, emphasising the contribution this paper makes to the literature.

\section{Digital On-Demand Working: The Capitalist Colonization of Digital Commons}

The speed at which digital technologies have been adopted and their transformative effect on economies is so profound that many have begun to call the present era the "fourth industrial revolution' (World Economic Forum, 2016). Digital technologies are clearly attractive to forprofit enterprises for many reasons. 'Big data' accelerates computing capacity beyond that of human operators. Digital on-line apps cut the overhead costs of capital (such as cars in the ridehailing industry). And social media's main benefit, from a corporate point of view, is not connecting people with each other but rather its ability to predict and exploit consumer behaviour for marketing purposes (Zuboff, 2019). 
Digital mediated open collaboration (Levine and Prietula, 2014) has offered unprecedented opportunity of developing new forms of non-hierarchical, open-access organizations; here its emancipatory potential has been realized in the development of collective endeavours such as Wikipedia or Linux (Stevenson, 2015; De Angelis, 2003). However, it has not taken long for the 'digital commons' to be integrated into capitalist modes of production and consumption, colonizing these new spaces and harnessing them to market logics (Ossewaarde and Reijers, 2017). A much discussed recent example is the rise of 'surveillance capitalism' that operates by using digital technologies for behavioural monitoring, employing this information to predict future behaviour for marketing purposes (Zuboff, 2019).

As a specific manifestation of this trend, the 'platform economy' allows enterprises to utilize technology so that they do not themselves provide services but merely link buyers and sellers in the marketplace, and receiving a fee in the process. A significant subset of the platform economy are firms that use on-demand work systems - managed through smartphone apps - to mediate between individual service providers and service users (De Stefano, 2015). These forprofit companies mobilize a de facto workforce, who are technically considered self-employed. Digitally parceled out microtasks have been around since Amazon launched its Mechanical Turk service in 2005, but the model has expanded significantly with the advent of smartphones (Hill, 2015). Firms do not need to pay workers during idle time, only the units of labour they perform. The largest on-demand work platforms number registered users in the millions (Scholz, 2016). For sure, if their workers were considered their 'direct' employees, Crowdsource, Crowdflower, Care.com and Uber would all be larger than any other existing employer in the service economy (Kessler, 2018).

Digital platform firms frequently extol the virtues of self-employment, entrepreneurship and financial independence. However, critics suggest there is a profound incongruence between the rhetoric of entrepreneurial freedom and the reality of precarious, low-paid work (Prassl, 2018: 9; Wood et al., 2019; Graham and Woodcock, 2019). Author (2017) lambasts the 'radical responsibilization' involved when firms shift the risks and costs of employment - usually covered by employers in the regular economy - onto workers themselves. Uber's business model pursues this principle to its logical conclusion, disavowing any responsibility for worker entitlements and benefits, whilst fervently fighting unionization (which is illegal for Uber drivers in the US, for instance). In a context of stagnating wages more generally, this is why some argue that on-demand working is one mechanism through which wealth inequality has 
increased, with a greater share of profits being distributed as dividends rather than worker income (Srnicek, 2016).

As they carefully avoid structuring themselves as formal 'employers', platforms are able to pay considerably below prevailing minimum wages, e.g. USD 1.00-5.50 per hour on Amazon Mechanical Turk (Berg, 2016) and as little as USD 3.99 per hour on Uber (Prassl, 2018: 61). Those who control the platform capture most of the value created by these workers; and at the same time capital owners enjoy relatively low overheads by corporate standards as they do not have to invest in plant or equipment (Scholz, 2016).

\section{Algorithmic Management}

Although not confined to the gig economy, management by algorithm is a salient feature of this business model. According to Mateescu and Nguyen (2019: 1), algorithmic management can be defined as "a diverse set of technological tools and techniques to remotely manage workforces, relying on data collection and surveillance of workers to enable automated or semi-automated decision-making."

Algorithmic management has multiple facets. It operates remotely through various forms of technological mediation, especially where apps are rented to private citizens (e.g., Uber drivers). It is highly computational, meaning that it runs through various forms of big data methods that allows for impressive surveillance capabilities. The use of smartphones has been central to this since it permits individualization (the worker owns the device rather than the firm) and near constant monitoring. Furthermore, the deployment of consumer rating systems means that workers are evaluated via the consumption moment itself, shifting this facet of appraisal away from the firm and onto an ostensibly 'private' transaction. Hence, and as Curchod et al. (2019) argue, this is no ordinary panopticon, because workers are not subject to the gaze of managers but by users themselves, which has implications for job security and rewards.

There is little research on how algorithmic management systems intersect with some very human power relationships in the platform economy. We argue that the clear tensions involved do not just emerge between human actors and non-human actants: this technology also has implications for decision accountability regarding hiring, appraising and firing that have previously been made by real people, like employers and managers. Whereas a human boss can be rendered accountable to unfair dismissal and follow due process to ensure fairness, an 
algorithmic manager obviously cannot. Even under the EU's recent General Data Protection Regulation legislation, companies are exempted from revealing the decision-making criteria used by algorithms for these kinds of decisions. Gig workers governed by AI thus often fall through the cracks of employment legislation both with respect to their employment status as well as protections from discrimination and unfair dismissal. We therefore need to consider how algorithms mesh with power struggles between employers and labour, managers and the managed. This will help address our question as to why there is so little effective industrial action in the gig economy.

\section{Enter Biopower}

In his later years Foucault argued that power was not simply exercised through sovereign force or even disciplinary techniques, but through managing bios or 'life itself', linking peoples' social existence to market forces, not just their paid labor time (Foucault, 2008; 2007; 2003). Foucault called this 'biopolitics'. The specific techniques involved are called biopower, a concept that has seen some application to workplaces (Author, 2014a; Moisander et al., 2018; Weiskopf and Munro, 2012; Munro, 2012). Biopower sees individuals 'marketise' their own private life activities including work, leisure, consumption, romance and life in general. Foucault developed the concept of biopolitics to describe a variant of power that no longer simply restrains or delimits individuals but invests in 'life itself', frequently expressed as (putative) free choice.

According to Foucault (2008), human capital theory - popularized by neoliberal economists is an exemplar of biopower. Under this paradigm, there are no longer employees, bosses, students, owners or managers per se. Instead, all individuals are conceptualized as 'micro capitalists' who constantly perform a cost/benefit calculation regarding their daily choices. In this respect, biopower consists of,

... generalizing the 'enterprise' from within the social body or social fabric [...] The individual's life itself - with his relationships to his private property, with his family, household, insurance and retirement - must make him into a sort of permanent and multiple enterprise (Foucault, 2008: 241).

The idea has proved useful in explaining how neoliberal economic theory has redefined contemporary organizations, especially in relation to the blurring of the work/non work boundary: the human capitalist, for example, is a permanent enterprise who never switches off 
(Moisander et al., 2018; Weiskopf and Munro, 2012) and considers all aspects of his or her life in purely economic terms. Importantly, this mode of regulation relies on 'formal' freedom and self-direction rather than disciplinary enclosure because life itself becomes the primary vehicle of subjugation. As Weiskopf and Munro (2012: 687) argue with respect to human capital theory, biopower infiltrates the everyday processes of individuals and regulates them without overt intervention: biopower implicitly "defines the frame within which choices can and must be made. It is associated with a specific type of organization, which allows freedom of movement but channels that movement and its flows in specific directions."

The architects of 'Uberization', as the diffusion of platform work systems is often called, have capitalized on this form of power and control in relation to labour, especially with the use of managerial algorithms. This form of management follows the worker in an ongoing and continuous fashion. Direction and monitoring are inserted into the worker's decision-making process, both on and off the job. The nudging technology involved (with the help of 'big data') seamlessly weds regulation with workers' daily living patterns, how they respond to a surge and the number of breaks they take. As a result, many gig economy workers find it difficult to differentiate labour time from personal time. This fits Foucault's concept of biopower very neatly, and is an excellent descriptor of how control functions in the industry, particularly given that no direct supervisors are present.

\section{Whither Resistance?}

This begs the question as to how platform workers respond to the negative aspects or 'externalities' of this biopolitical regulation. There have certainly been flashpoints of resistance to platform capitalism, including class action lawsuits against Uber in the US and intermittent industrial action, but by and large, collective resistance has been conspicuously absent (Kalleberg, 2018; Graham and Woodcock, 2019).

By resistance we mean the active attempt to oppose and/or reverse a specific power relationship (Author, 2008). It is worth noting that control and resistance in the workplace are often not separate entities but interconnected through complex processes (Mumby, 2005), a point we will return to in our discussion. In relation to our focal research site - Uber and its drivers - we ask why more drivers are not collectively opposing the increasingly draconian pay and conditions they face. The largely docile state of the workforce is clearly reflected in the paucity of labor regulations: to date New York City is the one jurisdiction in the world that has applied 
minimum wage laws to on-demand workers (a similar ordinance as recently passed in California was passed but is subject to legal challenges at the time of writing).

There are probably a number of reasons behind this absence of organized resistance. The gig economy lacks the typical support structures that can encourage organized opposition. Take, for example, space. As classic studies of the capitalist labour process reveal, the workplace is both a place where workers are subjected to disciplinary control but also come together as a collective unit, enabling occupational solidarity to emerge (Edwards, 1979). It is precisely where power is spatially productive that new forms of cohesion and resistance can develop (McKinlay, 2006). This is why unions, for example, tend to focus on certain collective spaces. But this kind of classic 'shopfloor' is remarkably absent in much of the gig economy. By design, the workforce, combined with technological assets that remain their property (be it a smart phone, a lorry, a car or a bicycle) constitute a myriad of fluid and moveable workplaces. Digital labour markets are lonely places, in which workers toil independently, in isolation, and sometimes in direct competition with one another (Johnston and Land-Kazlauskas, 2018).

Another factor for the lack of coordinated resistance could be the reluctance that some workers have with self-identifying as an employee: many drivers claim they are only using the ridesharing app as a fun and/or temporary way to earn extra income (Lee et al., 2015). The high turnover rates in platforms firms - where participants move in and out of different 'gigs' in a variety of sectors - disincentivise the effort to invest in community-building activities with coworkers or organizing labour interests therein (Johnston and Land-Kazlauskas, 2018).

Nevertheless, Uber drivers have many opportunities to meet, socialize or converse, be it on the road, in cafes, waiting points and - more importantly - in cyberspace, through social media and chatrooms. Indeed, there are several social media forums used by gig workers to share experiences, news and concerns on the job. So given that digital on-demand workers use the internet so extensively, should we not be seeing them turn to the web in order to facilitate the development of collective voice?

The potential, at least, for this has been noted. For example, Van Zoonen et al. (2016) found in an analysis of tweets from 433 digital platform users, one-third were related to work conditions. Clearly some of this digital chattering could fuel mobilized opposition in order to obtain better pay and conditions. For sure, the role of social media in coordinating dissent in other contexts, such as the Arab Spring, has been well documented (Eltantawy and Wiest, 2011). However, it appears that digital employers are not taking any chances in this respect, actively undermining 
social media use when it contravenes their socio-economic interests. A blatant example was Amazon enlisting an army of fulfillment-center employees to write positive comments about working in its warehouses (Coldewey, 2018); similarly, the company pays some of its warehouse workers to counter-troll anyone who tweets negative comments about pay and conditions in its vast warehouses (Johnston and Land-Kazlauskas, 2018).

The debate remains open on whether the internet on the whole either enables or discourages worker resistance (Thierer, 2014). More generally, the capacity of the 'digital commons' to generate genuine oppositional solidarity has been questioned, mainly due to the lack of human contact and shared space necessary to build social trust and a shared identity (Ossewaarde and Reijers, 2017). Some online expressions of criticism by professional workers amount to little more than coping strategies, 'safety-valves' that do not unsettle the dominance of the firm (Kärreman and Alvesson, 2009). Therefore the existence of online forums cannot be taken as prima facie evidence of effective resistance (Upchurch and Grassman, 2016).

This conspicuously apolitical situation is not without precedent, as studies have identified other 'hard to organize groups', particularly among conventional contingent workers. But even here alternative forms of opposition have been observed to some degree (Heery, 2009; Fine, 2015; Milkman and Ott, 2014). Therefore, we suggest that the gig economy appears to be a rather unique case, with its own reasons for the apathy and lack of collective dissent. So to address the research question motivating this paper (why does collective resistance fail to coalesce among on-demand workers in the platform economy?) we will now discuss our case study of Uber drivers in Australia.

\section{Method}

Uber was chosen because of its scale with over a million registered drivers worldwide and because it has become an icon for the so-called Uberization process, which is heavily reliant on algorithmic management. Uber is a leading player in this sector and also presents opportunities that arise from studying a 'paradigmatic case' (Flyvbjerg, 2006; Flyvbjerg, 2011). We argue it represents the ideal-typical dynamics of the gig economy for three reasons. First, the drivers' relationship with company management is almost completely mediated by computer interfaces. Second, drivers are isolated and have little or no physical contact with one another or with the company. Third, their 'IT literacy' (an indispensable condition to participate in the gig economy) offers them with opportunities to express views about work, to connect and build solidarity over social media forums. In other words, these workers could "turn to 
digital culture to crowdsource information that they don't get directly from their algorithmic boss" (Rosenblat, 2018: 202).

To investigate the behavior of Uber drivers in Australia we combined two qualitative methods. The first is a netnographic analysis (Kozinets, 2010) of the online forum 'uberpeople.net'. Established in April 2014 by drivers themselves, uberpeople.net has over one hundred thousand users and nearly 5 million posts, including more than 400,000 referring specifically to Australian cities. Australian drivers also contribute elsewhere on the site. The uberpeople.net forum presents a large resource of naturally occurring and publicly-accessible data. Social media communication is often secretive (Richards, 2016) so using this site helped overcome that challenge to some extent. We used a webscraper to download and examine 2,183 forum posts that included words indicative of disgruntlement or protest. Additional netnographic data were collected through Facebook driver groups too.

Forum users rarely write at great length, usually communicating in straightforward questionand-answer posts (Rosenblat, 2018). So to enrich our data-set, additional information was gathered from a second method, 21 semi-structured interviews. This provided an opportunity to hear drivers speak at greater length about their motivations, experiences and challenges in their working lives. Interviewees were recruited via advertisement on uberpeople.net and in several Facebook Groups, with interviews taking place between December 2016 and March 2017. Interviews were coded according to themes raised by interviewees, focusing on issues/grievances with Uber and the thematic of collective action.

Data were analysed in a two-step process. Firstly, common themes and patterns are identified using a grounded theory approach (Glaser and Strauss, 1967; Corbin and Strauss, 1998). The aim of this initial step was to develop a second interpretive move, yielding categories that could be used to illuminate the data, demonstrating their relevance by saturating them with a number of appropriate cases. In practice we identify a number of observed, recurrent phenomena that seem to characterize the power relationship between Uber drivers and the company.

\section{Findings}

Findings are now presented in relation to key themes associated with the power/resistance dynamic that we suggest is indicative of how gig economy workers are regulated under platform capitalism. In particular, we identified data that is illustrative of how algorithms display biopolitical features that may regulate workers and block either their desire for or 
ability to collectively resist as discussed above. In doing so we have categorised the data into four significant themes.

\section{Resignation and Hopelessness}

We found that Uber Australia's algorithms are firmly in control of the drivers' working lives. They significantly delimit their choices, coaxing them onto the road at busy times, punishing them for refusing to accept rides, 'sacking' them for negative customer ratings and so-forth. Drivers also said that they 'lived' with the app, and it formed a dominant background to their daily living patterns. While this was meant to be empowering - officially at least - it appeared to create a sense of hopelessness among workers. Most drivers were resigned to the low pay and did not believe this could be improved through collective action. Given the algorithms involved, Uber is typically described in fatalistic terms: an omniscient and unforgiving entity to which drivers do not belong, yet sets the rules of the 'game'. Moreover, drivers often feel that they have little choice but to comply and play along with this game:

There's not a body of anything that can raise all these concerns with Uber. Uber have the control. (Driver interview)

Uber is a horrible company. I think many of us will agree with that but they're entitled to do what they do. (Driver interview)

This resignation inevitably undermines the possibility of considering collective action. When the idea is entertained, it leads to a form of self-censoring, based on the belief of the hopelessness of the initiative.

It's very difficult for drivers to organise collectively [...] despairing is probably a bit of an exaggeration but I don't have a lot of hope for being able to do that and that's a victory for them [Uber] because that's exactly what they want. They want drivers to not have the ability to organise, they want drivers to not have the ability to act collectively, and they're getting it. (Driver interview)

Other drivers noted that social isolation and fragmentation was an intrinsic part of the experience of driving for Uber. One said, “I don't think there's many drivers that really know each other". Another admits to having never had contact with any other driver. Apart from some WhatsApp groups that meet in person there is little evidence of coordinated attempts to meet at all let alone organize. Generally, the mood was one of resignation:

They just expect you to give up, they expect you to give up (Driver interview).

They don't respond to complaints at all, no. They don't want to respond to complaints (Driver interview). 
These WhatsApp groups and Facebook groups - I mean they threaten Uber's rule in the sense that we have the opportunity to become a collective if there's a political will amongst the drivers which I don't necessarily think there are (Driver interview).

Forum posts have the same resigned tone:

When the realization kicks in that none [sic] gives a tomato about their little strike and nothing will result of it, except your time wasted on a ordinary Wednesday. The app will still work and there will be some drivers making some extra on the surge, that's all. I pray for you guys and feel second hand embarrassment from the thought of how the event will unfold. Just like Taxi drivers striking to ban Uber, resistance will be futile. And even hypothetically, the strike hurts Uber, how exactly is striking a blow to one of your only two business partner [sic] that is already hurting going to magically increase your wage? It won't, if anything it will decrease it as Uber has to show financial result. The more you strike, the harder the squeeze will be on your rate to make up for any potential damage. (User AveragePerson)

Not all drivers arrived to the conclusion that resistance is futile or even that Uber was a target to be resisted in the first place. Forum user AveragePerson, for example, appears to have internalized the rhetoric that what's good for Uber is unquestionably good for drivers too. Other drivers draw on the discourse of 'the market' to the same effect, believing that the inexorable forces of supply and demand will compel Uber to increase pay. From this perspective, resistance looks irrational and counter-intuitive to the shared pursuit of economic self-interest:

Uber really hates a driver not accepting a ride, it will eventually be forced to substantially increase our rates and earnings. Watch it increase rates. Ain't no way Uber will survive with this crap if giving us .60 cents a mile or $.40 \mathrm{c}$. (User Ozzyoz)

\section{Distance and Isolation}

Another prevalent theme in the data was Uber's desire to keep its workforce at arm's length, both individually isolated from each other and the company itself. This was achieved not only legally - by being legally classified as independent business owners - but also by creating the impression that the company was aloof and inaccessible. Management by algorithm was very important for doing this. Consequently, drivers' daily movements are shaped by algorithm as are their formal channels for recourse:

You can't pick up a phone and talk to someone (Driver interview).

It's difficult the way they've got it because it's just like, if it's an issue that's not related to all their points it's difficult to talk to them. Unless it's an issue that they have in their drop box (Driver interview).

You get more answers on the Uber forum than from Uber itself (Driver interview). 
I'm just going to have to wait here until you let me know when [overdue payments] come in. Otherwise you're going to have 150 drivers in here before four o'clock (Driver interview).

We interpret this excerpt as evidence of how biopower - as the regulation of life itself in relation to the controlling party - monitors the interactions between the driver and company. Because this was preset by the algorithmic feedback system, drivers had little choice but to accept the relationship. This is also consistent with Rosenblat's (2018: 192) observation that, "drivers repeatedly meet with the pain of realizing that their frustrations don't merit much more than auto-replies from Uber Support". Rosenblat argues that this stonewalling is also a direct cause of the prevalence of online chatting: "distanced from their employers, drivers turn to digital culture to crowdsource information that they don't get directly from their algorithmic bosses" (Rosenblat, 2018: 202). Only one interviewee persisted with the company until heard to her satisfaction.

\section{Gaming the System}

Drivers are encouraged to play by Uber's rules for higher pay, treating it almost as a game. Once again, this represents a form power that evokes the life skills of workers, their ingenuity and innovativeness, as part of the control system. Management algorithms provide the medium through which this is accomplished. Most are well aware of that the company's tactics are designed to suppress their interests yet seem to go along with the limited options put before them to increase earnings, mostly by driving when fares are 'surging', i.e. increased by algorithm in response to high passenger demand. 
Notwithstanding their aversion to direct conflict with Uber, many drivers openly discuss ways of gaming the Uber system to make it work better for themselves. This often goes beyond what the company would regard as legitimate. For example 'longhauling', taking a longer than necessary trip to take advantage of Uber's switch to upfront pricing, means drivers spend proportionally more of their shift carrying a passenger and therefore earning money while the passenger is not charged any extra so, unless she or he is in a hurry, is not adversely affected. User koyotemohn said, for example:

So if the trip is more than 3 miles...find a way to make it 5. It's these little details that accumulate into larger bounties

User 3.75 replies:

Correct. Base rate is no longer your enemy but your friend. Be in control, use all tools whenever possible. Make $u$ turns if necessary, if pax complains tell them you're unfamiliar with the area

These workers are exploiting loopholes and blind spots, manipulating and identifying workarounds to the algorithm system (Bader and Kaiser, 2019). It appears optimistic, but looks can be deceiving. While doing so they are drawing on their own personal insights and skill (a clear indicator that biopower is being exercised) and implicitly valorizing the very algorithm that they are gaming. In the end, it they who are being gamed by the algorithm and company.

\section{Deriding 'Uber Ambassadors'}

The excerpts presented above are drivers who believe that pushing for higher pay is futile and that tactical moves within the system are better pay. They still remain rather negative about the firm. However, that is not the case for all drivers. Some espouse and endorse the rhetoric of Uber so completely that other drivers believe that they are, like Amazon's Warehouse Ambassadors, being paid to encourage their peers to work longer and harder.

A driver who goes by the username mulder99 especially embodies the values that Uber seek to instill in its workforce: namely, that the best thing drivers can do to better their situation is to simply work longer hours. It does not appear that mulder99 really is an 'Uber Ambassador' because in some posts he is seen to make remarks critical of the company and in others he claims to drive for multiple rideshare companies. Mulder99's profile picture is the Marvel character Ant-man, a self-deprecatory reference to the word 'ants' that some drivers use to describe themselves on the forum. He is very vocal on the forum and as a result generates much reaction from other drivers, which reveals how most drivers despise this level of loyalty. On a 
number of occasions, user Spy For Uber (whose very username appears to be openly disparaging mulder99) says:

he is amazing our mulder99 he's the most breathtaking driver on the australia uber fleet mulder99 understands that the only thing in life is only uber * he has his priorities right \& doesn't worry about family or friends or anything. his friends are the riders he spends 17 hours $\mathrm{z}$ day with for seven days a week and keep your comments to yourself coz mulder99 is not a big head egotistical show off no \& no it's not fair you called him a narcissist it's not true he has great pride in showing you his little wins after doing 17 hours of driving going back to an empty flat for a five or six hour turn around to be weary eyed back on the road again we love you mulder99 \& don't worry about those sour grapes tissue box drivers

In another thread mulder99 offers some free advice:

Give it away if you can't make money on Mardi Gras You either have no idea or not researching on how to UBER

To which Spy For Uber responds:

See this is the type of person we want forever on our uber fleet! Mulder99 never whinges, he is like a machine, he keeps going \& going. Mulder99 his work ethic is Fantastic. Our staff here in the city xmarvel at his performance. the rest of you need to smarten up your act, why do you care if you get a lot of Glitter in your car from Mardi gras, most of your cars are rentals. we feel for you too mulder99 knowing that because of the $12 \mathrm{hr}$ regs you would like to push on to your old days doing 17 straight hours. we might have to make an exception for you mulder99 as your work is breathtaking. your a brilliant uber driver \& you almost could keep the whole of Sydney moving just by your lonesome.

Not everyone is as cynical as Spy For Uber. User Uber TopGun takes mulder99's helpfulness at face value:

Maybe Mulder99 can help with this issue and with his contacts at Uber Admin Mgmt, maybe Mulder99 can get uber to be proactive and have this fixed up? Can you sort this Mr Mulder99 for Slazrnger \& others?

To which mulder99 responds:

You are mostly likely the closest car around due to traffic won't be any available cars on Anzac bridge. The pax will generally wait unless they impatient and grab a taxi from the rank

And another from user RustaSam:

Mulder99 is a hard worker. And good on him. Some people just don't have the work ethic he has. You need discipline to make money. You need a plan. Good on you Mulder99 keep up the good work. Thank you for your 
contributions to the forum. Some of you should take a hard look at yourselves you may have Tall poppy syndrome

Here we can see how the social media forum was certainly a format for expressing dissenting views regarding Uber and its management systems. However, Spy For Uber's cynicism is a good example of how this dissatisfaction is displaced or redirected onto other workers perceived to be ambassadors, rather than the company. This is turn provokes more sympathetic views from other drivers, effectively fragmenting any potential solidarity that could have emerged against the company. Moreover, mulder99 in his own way is causing problems for drivers who listen to his advice, by selling false hope. By broadcasting hidden routes and highearning sites, they are no longer hidden, which dilute their benefit for any subsequent drivers make by following him.

\section{Discussion: Biopolitical Algorithms at Work}

Our analysis of online conversations and of informants' reports shows that one reason why collective opposition does not coalesce among the Uber drivers we studied is because management by algorithm effectively isolates and fragments the workforce. In the words of a driver quoted above, and alluding to irony of the situation, you simply cannot get the company on the phone. This means that the social distance that is supposedly inherent to this kind of work is reinforced and reproduced by the use of algorithms and of IT mediated communication.

Moreover, the use of algorithms to assign, optimize and evaluate tasks (Lee et al., 2015) has the additional effect of depersonalizing authority. Commands and rules that would likely generate opposition and social tensions if enacted by human managers are accepted as indisputable hurdles that can be navigated and 'gamed' rather than resisted or contested.

We suggest the best way to theoretically explain these phenomena is with the help of Foucault's (2008) notion of biopolitics. Each of the four themes described above demonstrate biopower at work in the gig economy. First, the sense of an all-encompassing power that tracks everyday life processes gives the control a sense of inevitability, sparking a mood of resignation. Second, the depersonalized distance of management by algorithm makes it difficult to confront the company and also isolates workers, meaning they are on their own and once again blurring the work/life boundary. Third, some drivers accept the algorithm - with the above preconditions and attempt to game it to their own benefit, thus drawing on skills that are not officially part of the job. And fourth, management by algorithm displaces resistance onto other workers via the 
social media platforms, fragmenting potential solidarity and reproducing the other facets of this biopolitical control matrix.

Although organizational struggle (especially online) did forge connections between workers that might not otherwise have happened, it was not as widespread as one might expect and definitely did not form a substantive network of organized resistance. The majority of forum users do not participate with the intention of engaging in organized dissent but merely as a form of employee information sharing (Viveros et al., 2018).

This dearth of collective solidarity is - in part at least - a product of the biopolitical algorithmic management used by Uber, which circumscribes drivers' options while constantly nudging them to working harder. Drivers' complaints are met with the canned response, "this is designed to make you more successful". This almost implies a form of social Darwinism; the idea that market competition, lightly regulated by impersonal agencies, will select the best solutions, sparking individual self-improvement and self-reliance. The approach remains consistent with Uber's public pronouncements about encouraging entrepreneurialism and describing drivers as 'partners' rather than employees or workers. However, as an instrument of biopower - where regulation is embedded into the life process itself - the algorithm is far more effective than efforts to create a 'culture of entrepreneurialism' which drivers can, and do, resist through cynicism.

Key to the power exercised over Uber drivers - which shapes their resistance too - is the dematerialization of the antagonist (the capitalist firm), which is replaced by an apparently neutral and impersonal force, an algorithm that mediates the drivers' interactions with both customers and the company. Its complexity, which makes it an impenetrable 'black box', means that managerial decisions are largely inscrutable and therefore incapable of being contested or appealed. Moreover, this leads drivers to forget that the algorithm is a bundle of rules and policies devised with the intent of maximizing utility for one party (the owners of the platform), rather than operate as an impartial arbiter. Many drivers accepted this technological infrastructure - both the algorithm and app that matches rides and riders - as the uncontestable parameter for working with the company. More surprisingly, many perceived it to be inherently fair because drivers assume algorithms always work as promised and in a consistent fashion (in actual fact, Uber regularly benefits from uncorrected errors that nearly always work to the company's advantage). Drivers typically see it as a neutral user-interface - helping them to 
quickly make decision about whether to get a ride and how to complete it, a useful ally or at best a game to be mastered.

Algorithmic management is an evolution of what Foucault (2007) called government from a distance, an important feature of biopower. It seeks to change and regulate behavior without resorting to crude methods of prohibition and punishment. Algorithmic management specializes in this due to its unusual opacity. For Uber's drivers, it is unlikely that even total transparency around the algorithmic rules would help since it requires such a high degree of computing expertise to understand how and why certain 'nudges' were made.

Ironically, this ultra-electronic depersonalization and distance did not transform drivers into robots or automatons, but the exact opposite, which is why we consider it biopolitical. Drivers had to draw on their personal life skills, ingenuity and cunning - both on and off the clock - to get the job done and game the system. However, since Uber's drivers have no real person to complain to and are controlled by a 'neutral' algorithm, these energies are not used for contesting the company. Rather, occasional resistors identify and criticize coworkers who are deemed to be 'champions' for the company, and vent on them instead. This is displaced resistance, where drivers try to rehumanize their sense of disgruntlement by directing it at another driver - the most proximate human target available in some cases - rather than the company. This has the unexpected, but to Uber beneficial, effect of causing workers to squabble among themselves rather than mount a unified challenge to the firm.

Drivers' attempts to game the system also had notable consequences. Workers used the pregiven parameters to try and outsmart the algorithm, devising unforeseen ways to maximize income and not just follow Uber's playbook (e.g., getting on the road and driving during the surge). We saw this in relation to the practice of 'longhauling' (artificially extending a trip to take advantage of the 'switch to upfront' pricing option), which manipulates the algorithm to increase revenues at the cost of Uber, without charging the passenger extra. Interestingly, even this attempt to manipulate algorithmic management is determined by the biopolitical frame imposed by the company. Uber drivers cannot use taxi drivers' time-honored trick of 'taking the long way', because of the negative user-feedback may jeopardize their job.

All this gaming had little impact on the firm as a whole, because it tends to be isolated and individualistic. Here we can note the apparent contradiction between drivers being, for the most part, fatalistically docile about the prospect of Uber paying more while at the same time displaying inventiveness and tenacity when it comes to gaming the system. We might see this 
as a digitalized version of the 'making out' games Burawoy (1979) famously observed in a factory setting over 40 years ago. As Burawoy also observed, exploiting blind spots in the labour process to maximize income was counterproductive, since it sublimated the desire to resist domination in any confrontational fashion.

The low identification with the company, which in a traditional context might fuel resistance (Humphreys and Brown, 2002), is in this case yet another factor that undermines collective opposition. The high turnover rate and low barriers to exit (Rosenblat, 2018) impede the likelihood that enough unity could be generated for resistance. Even if some drivers rely on Uber as a single source of income, many are also side-hustlers, supplementing their income from another occupation, or 'hobbyists' who do it mainly for the social interaction. In other words, the tenuous relationship between drivers and Uber is a barrier to the formation of worker solidarity. We have noticed how identification or investment in the occupation is frequently derided as fake or contrived. Since drivers only become Uber's 'employees' when logged into the app, and technically 'resign' from their post every time they log off, Uber is often not understood as an employer, but a sort of impersonal marketplace. Algorithms are 'the invisible hand' of this marketplace.

\section{Conclusion}

Our paper has argued that algorithmic management in the gig economy can been interpreted as a form of biopower in which life itself is enrolled and put to work. The manner in which it does is anathema to the kind of solidarity required for collective resistance and industrial action. Hence why workers in this sector - now infamous for its exploitation and economic insecurity - seldom summons meaningful opposition to obtain better pay and conditions. In the face of such power relations, it is easy to see why exit and loyalty are perceived to be the only viable options available. And for those who find these two responses to the gig economy undesirable, social media forums provide a space to vent and displace their disgruntlement onto fellow workers, rather than forge social bonds of rebellion.

The algorithmic techniques of biopower we have examined do not function in a vacuum. They are clearly aided and abetted by the 'self-employment' status of drivers, a fundamental aspect of the platform business model. And by law, Uber drivers cannot negotiate collectively because they are not employees but independent business owners. Some jurisdictions go even further and forbid them to form a trade union, which has not completely eradicated the alt-labour movement in this sector, but certainly rendered it very difficult to achieve. In the face of such 
forces, not even the social media forum we investigated could build a collective sense of opposition (notwithstanding the highly negative views some drivers had of the company).

It is ironic that biopower - the power over and through living human beings - is at its most potent when guided through an ultra-dehumanizing algorithmic app that appears robotic, neutral and devoid of life. This rather lifeless instrument of domination allows gig firms to access and harvest wider life processes as a key resource, including the ingenuity, downtime and everyday knowhow of workers. And in the end, drivers shoulder the risks, externalized costs and responsibilities for this business model, often drawing on other jobs, governmental welfare services and family networks in order to participate. For this reason, we suggest, gig economy organizations like Uber not only instrumentalize bios through its algorithms, but also display parasitical tendencies. Perhaps this parasitism is characteristic of platform capitalism more generally, mining and riding on the 'social commons' (Hardt and Negri, 2004), thriving on the fringes, rather than having anything to do with genuine 'sharing'.

The actual computer codes that govern these algorithms are vigorously defended from scrutiny by firms like Uber, Deliveroo, Taskrabbit and Lyft. As these platforms expand into our lives, algorithmic biopower moves into the hands of platform owners. While only a minority of the workforce are engaged in app-based jobs, the acceleration of AI-enabled algorithms represents a qualitative shift in power relations are exercised in organizations. The kind of biopower coalescing here is far more insidious than anything existing when Foucault coined the expression in the 1970s. Therefore, new conceptual and practical tools are urgently required if workers are to effectively resist this troubling development in neoliberal economies and beyond. This includes a comprehensive understanding of the complex forces at work. Towards this end, we hope our paper helps. 


\section{References}

Bachrach P and Baratz MS. (1962) Two Faces of Power. The American Political Science Review 56: 947-952.

Bader V and Kaiser S. (2019) Algorithmic decision-making? The user interface and its role for human involvement in decisions supported by artificial intelligence: The Interdisciplinary Journal of Organization, Theory and Society The Interdisciplinary Journal of Organization, Theory and Society. Organization 26: 655-672.

Berg J. (2016) Income security in the on-demand economy: Findings and policy lessons from a survey of crowdworkers. Conditions of Work and Employment Series. Geneva: ILO.

Burawoy M. (1979) Manufacturing Consent: Changes in the Labor Process Under Monopoly Capitalism, Chicago: University of Chicago Press.

Coldewey D. (2018) What is this weird Twitter army of Amazon drones cheerfully defending warehouse work? Available at: https://techcrunch.com/2018/08/23/what-is-thisweird-twitter-army-of-amazon-drones-cheerfully-defending-warehouse-work/.

Corbin JM and Strauss AL. (1998) Basics of qualitative research: techniques and procedures for developing grounded theory, Thousand Oaks, CA: SAGE.

Curchod C, Patriotta G, Cohen L, et al. (2019) Working for an Algorithm: Power Asymmetries and Agency in Online Work Settings. Administrative science quarterly.

De Angelis M. (2003) Reflections on alternatives, commons and communities. The Commoner 6: 1-14.

De Stefano V. (2015) The rise of the just-in-time workforce: On-demand work, crowdwork, and labor protection in the gig-economy. Comparative Labor Law and Policy Journal 37: 471 .

Edwards R. (1979) Contested Terrain, New York: Basic Books.

Eltantawy N and Wiest JB. (2011) The Arab spring| Social media in the Egyptian revolution: reconsidering resource mobilization theory. International Journal of Communication 5: 18.

Fine J. (2015) Alternative labour protection movements in the United States: Reshaping industrial relations? International Labour Review 154: 15-26.

Author (2008) ...

Author (2014a) ...

Author $(2014 b) \ldots$

Author (2017) ...

Flyvbjerg B. (2006) Five Misunderstandings About Case-Study Research. Qualitative Inquiry 12: $219-245$.

Flyvbjerg B. (2011) Case Study. In: Denzin NK and Lincoln YS (eds) The SAGE Handbook of Qualitative Research. Thousand Oaks, Ca.: SAGE, 301-316.

Foucault M. (2003) Society must be Defended: lectures at the Collège de France, 1975-76, London: Palgrave Macmillan.

Foucault M. (2007) Security, territory, population: lectures at the College de France, 197778, London: Palgrave Macmillan.

Foucault M. (2008) The birth of biopolitics: lectures at the Collège de France, 1978-1979, London: Palgrave Macmillan.

Glaser BG and Strauss AL. (1967) The discovery of grounded theory: strategies for qualitative research, Chicago, IL: Aldine Pub. Co.

Graham M and Woodcock J. (2019) The Gig Economy: A Critical Introduction, Cambridge, UK: Polity Press.

Hardt M and Negri A. (2004) Multitude, London: Penguin.

Harvey D. (2005) The New Imperialism, Oxford: Oxford University Press. 
Heery E. (2009) Trade unions and contingent labour: scale and method. Cambridge Journal of Regions, Economy and Society 2: 429-442.

Hill S. (2015) Raw Deal: How the "Uber Economy" and Runaway Capitalism Are Screwing American Workers, New York: St. Martin's Press.

Hirschman AO. (1970) Exit, voice, and loyalty: Responses to decline in firms, organizations, and states, Harvard, MA: Harvard University Press.

Humphreys M and Brown AD. (2002) Narratives of organizational identity and identification: A case study of hegemony and resistance. Organization Studies 23: 421-447.

Johnston H and Land-Kazlauskas C. (2018) Organizing on-demand: Representation, voice, and collective bargaining in the gig economy. Conditions of Work and Employment Series. Geneva: ILO.

Kalleberg AL. (2018) Precarious lives: Job insecurity and well-being in rich democracies, New York: John Wiley \& Sons.

Kärreman D and Alvesson M. (2009) Resisting resistance: Counter-resistance, consent and compliance in a consultancy firm. Human Relations 62: 1115-1144.

Kessler S. (2018) Gigged: The Gig Economy, the End of the Job and the Future of Work, New York: Random House.

Kozinets R. (2010) Netnography: Doing Ethnographic Research Online, London: SAGE.

Lee MK, Kusbit D, Metsky E, et al. (2015) Working with machines: The impact of algorithmic and data-driven management on human workers. Proceedings of the 33rd Annual ACM Conference on Human Factors in Computing Systems. Seoul: ACM, 1603-1612.

Levine SS and Prietula MJ. (2014) Open collaboration for innovation: Principles and performance. Organization Science 25: 1414-1433.

McKinlay A. (2006) Managing Foucault: genealogies of management. Management \& Organizational History 1: 87-100.

Milkman R and Ott E. (2014) New Labor in New York: Precarious Workers and the Future of the Labor Movement, Ithaca, N.Y.: Cornell University Press.

Moisander J, Groß C and Eräranta K. (2018) Mechanisms of biopower and neoliberal governmentality in precarious work: Mobilizing the dependent self-employed as independent business owners. Human relations 71: 375-398.

Mumby DK. (2005) Theorizing Resistance in Organization Studies. Management Communication Quarterly 19: 19-44.

Munro I. (2012) The Management of Circulations: Biopolitical Variations after Foucault. International Journal of Management Reviews 14: 345-362.

Nguyen A and Mateescu A. (2019) Explainer: Algorithmic Management in the Workplace. Data \& Society.

Ossewaarde M and Reijers W. (2017) The illusion of the digital commons: 'False consciousness' in online alternative economies. Organization 24: 609-628.

Prassl J. (2018) Humans as a Service: The Promise and Perils of Work in the Gig Economy, Oxford: Oxford University Press.

Richards J. (2016) Netnographical methods and the challenge of researching hidden and secretive employee social media practices. In: Townsend K, Loudoun R and Lewin D (eds) Handbook of Qualitative Research Methods on Human Resource Management: Innovative Techniques. Cheltenham, UK: Edward Elgar, 92.

Rosenblat A. (2018) Uberland: How Algorithms Are Rewriting the Rules of Work, Oakland, Cal.: University of California Press.

Scholz T. (2016) Uberworked and underpaid: how workers are disrupting the digital economy, Cambridge, UK ; Malden, Mass.: Polity Press. 
Shell ER. (2018) The Job: Work and Its Future in a Time of Radical Change, New York: Crown.

Srnicek N. (2016) Platform Capitalism, Cambridge: Wiley.

Stanford J. (2017) The resurgence of gig work: Historical and theoretical perspectives. The Economic and Labour Relations Review 28: 382-401.

Stevenson N. (2015) Post-citizenship, the New Left and the democratic commons. Citizenship Studies 19: 591-604.

Thierer AD. (2014) The Case for Internet Optimism, Part 1 - Saving the Net from its Detractors. The Next Digital Decade: Essays on the Future of the Internet.

Upchurch M and Grassman R. (2016) Striking with social media: The contested (online) terrain of workplace conflict. Organization 23: 639-656.

van Zoonen W, Verhoeven JWM and Vliegenthart R. (2016) How employees use Twitter to talk about work: A typology of work-related tweets. Computers in Human Behavior 55: 329-339.

Viveros H, Kalfa S and Gollan PJ. (2018) Voice as an Empowerment Practice: The Case of an Australian Manufacturing Company. Advances in Industrial and Labor Relations, 2017: Shifts in Workplace Voice, Justice, Negotiation and Conflict Resolution in Contemporary Workplaces. Bingley, UK: Emerald, 91-112.

World Economic Forum. (2016) The future of jobs: Employment, skills and workforce strategy for the fourth industrial revolution. Global Challenge Insight Report, World Economic Forum, Geneva.

Weiskopf R and Munro I. (2012) Management of human capital: discipline, security and controlled circulation in HRM. Organization 19: 685-702.

West DM. (2018) The future of work: robots, AI, and automation, Washington, D.C.: Brookings Institution Press.

Wood AJ, Graham M, Lehdonvirta V and Hjorth I (2019) Good gig, bad gig: autonomy and algorithmic control in the global gig economy. Work, Employment and Society 33: 5675.

Yu S and Peetz D. (2019) Non-Standard Time Wage Premiums and Employment Effects: Evidence from an Australian Natural Experiment. British Journal of Industrial Relations 57: 33-61.

Zuboff S. (2015) Big other: surveillance capitalism and the prospects of an information civilization. Journal of Information Technology 30: 75-89.

Zuboff S. (2019) Surveillance Capitalism and the Challenge of Collective Action. New Labor Forum 28: 10-29. 